\title{
Estimation of G6pd Status in the Rajbangshi Population of Sushrutanagar
}

\author{
Anindya Dasgupta ${ }^{1}$, Tanushree Mondal ${ }^{2}$, Asok Kumar Datta ${ }^{3}$ \\ 1. Professor, Department of Biochemistry, National Medical College, Kolkata, West Bengal \\ 2. Assistant Professor, Department of Community Medine, N.R.S. Medical College, Kolkata, West Bengal \\ 3. Associate Professor, Department of Pediatrics, Bankura Sammilani Medical College, Bankura, West \\ Bengal
}

\begin{abstract}
The Glucose 6 Phosphate Dehydrogenase (G6PD) deficiency renders the cells susceptible to severe hemolysis under oxidative stress producing conditions. Due to considerable genetic heterogeneity it is found to be distributed in an unequal manner in different parts of the world including India. The present study was undertaken to find the distribution of G6PD deficiency in the Rajbangshi population group of Sushrutanagar, Darjeeling district. The Rajbangshis are one of the oldest tribes residing in North Bengal. A quantitative assay of the G6PD activity was performed in the Rajbangshi population and the non Rajbangshi control population of the same area. The G6PD deficiency was found in 12 percent of the Rajbangshi population studied which is significantly higher than the value of 3.3 percent found in the controls with the lower and upper confidence limit for the population Odds ratio being 3.58 and 25.93 respectively at $95 \%$ confidence interval. This high rate of G6PD deficiency in the population group studied poses them to a greater risk for several oxidative stress producing conditions including some commonly used antimalarial drug like Primaquin.
\end{abstract}

Key Words : Glucose 6 Phosphate Dehydrogenase (G6PD) deficiency, Rajbangshis, Ethnicity.

\section{Introduction}

Glucose 6 Phosphate Dehydrogenase (G6PD) is an important enzyme in the hexose monophosphate (HMP) shunt pathway of glucose utilization ${ }^{1}$. The HMP shunt provides NADPH which along with other cellular antioxidants is utilized to neutralize the hydrogen peroxide $\left(\mathrm{H}_{2} \mathrm{O}_{2}\right)$ and hence protect the Red Blood Corpuscle (R.B.C) membrane from hemolysis, particularly under the conditions which produce oxidative $\operatorname{stress}^{1}$ in the cells. The enzyme is present abundantly in R.B.Cs, liver, adipose tissues, adrenal cortex and gonads ${ }^{1}$. In the persons having low G6PD activity the R.B.Cs are much prone to hemolysis, particularly under conditions which produce oxidative stress in the cells, e.g. bacterial infection and exposure to certain drugs like aspirin, mepacrine, primaquine, sulphadoxine etc ${ }^{2,3}$. On the other hand the G6PD deficiency is found to protect the population against the Falciparum Malaria ${ }^{1}$. So, this enzyme has been an important sector of research all throughout the ages and throughout the world. The deficiency of this enzyme is the most common congenital defect in the HMP shunt pathway ${ }^{4}$ and is transmitted in an X linked recessive manner by heterozygous females, while the sufferers are mainly the males ${ }^{5}$. This deficiency is found to be distributed unequally among different races in the world. Highest incidence is in Kurdish Jews which equals to about 60 percent, followed by 15-30 percent in Negroes, 13 percent in Parsees of Mumbai ${ }^{2}$. The deficiency is also prevalent in the West and East Africa, Greece, Mediterranean people, China(specially the Li population) ${ }^{6}$, Japan, North West India, Srilanka ${ }^{2}$ etc. Among these the black people of Africa and the Japanese (10.8 percent Shan Group of Indonesia and Malaysia) are more susceptible ${ }^{7}$ and about 100 million people are deficient in this enzyme ${ }^{8}$. India is a country belonging to a heterogeneous population group for ages. In India this deficiency has been found to be present in 2-5 percent of the general population ${ }^{9}$. The Nagas and Hmars of the North Eastern India have reported G6PD deficiency to a substantial amount. ${ }^{10}$. The other groups of the Indian population where G6PD deficiency is prevalent are the Punjabis, the Sindhis, the Lohanas, and the Kutchis apart from the Parsees ${ }^{11}$.

Keeping these facts in mind, we hypothesized that the indigenous population group living in North Bengal might exhibit a different pattern of G6PD deficiency also. Accordingly the study on the distribution of G6PD deficiency was carried out in the 'Rajbangshi' population of Sushrutanagar of District Darjeeling of the West Bengal state. The total area of the Sushrutanagar has a population of 1,299,91 covering an area of 30.75 sq.km (as per census, 1991, data obtained from Matigara No.1 village Panchayat) 15-20 percent of which comprise of the "Rajbhansis", a particular tribe residing here for decades. They are, in fact, one of the oldest tribes of the North Bengal adding significantly to the cultural and economical growth of the area. G6PD activity in them was measured to find out the prevalence of the deficiency of this enzyme in them. 


\section{Selection of patients}

\section{Materials And Methods}

The present study was carried out in 100 persons selected randomly from the Rajbangshi population. Among them sixty were males and forty were females. All of them were free from any disease at the time of test with no history of any chronic disease. 60 non Rajbangshi people were selected from the non- Rajbangshi populations residing in the same area in a randomized manner. Forty of them were males and twenty of them were females. All of them were healthy and were free from any diseases at the time of test with no history of any chronic disease. Informed consent was obtained from the participants and the study was carried out according to the Helsinki declaration 1975. The study was approved by the institutional ethical committee.

\section{Measurement of G6PD activity}

The quantitative assay for the G6PD activity in the present study was done by the reagents supplied in the Lyozyme kinetic kit provided by the Vital Diagnostics (P) Ltd, Mumbai ${ }^{12,}$.

\section{Principle of the test}

Glucose 6 phosphate is oxidized in presence of $\mathrm{NADP}^{+}$and the enzyme Glucose 6 Phosphate dehydrogenase into 6 phosphogluconate. In this reaction the NADP ${ }^{+}$is reduced into NADPH and $\mathrm{H}^{+}$. The absorbance of the NADPH is measured in a spectrophotometer at $340 \mathrm{~nm}$ at one minute interval for four times. The rate of change of the absorbance is calculated and calibrated against a factor provided in the kit manual and the hemoglobin concentration to calculate the activity of the G6PD enzyme per gram of hemoglobin.

\section{Reagents provided}

1) G6PD reagent 1

2) G6PD reagent 2

3) G6PD reagent 3

Coenzyme and substrate.

Buffer.

$$
\text { Lysing reagent. }
$$

\section{Preparation of working reagent}

$1.0 \mathrm{ml}$. of G6PD reagent 2 (buffer) is added to the bottle of G6PD reagent 1 (Coenzyme and substrate), mixed well and used after five minutes.

\section{Method of the test}

\section{Preparation of the hemolysate}

For both cases and controls, $2 \mathrm{ml}$. of blood sample were collected in an EDTA vial. From this $0.1 \mathrm{ml}$. of whole blood was added to $2 \mathrm{ml}$. aliquots of physiological saline (0.9percentNacl) and washed three times. Now $0.5 \mathrm{ml}$. of G6PD reagent 3 (Lysing reagent) precooled at 2-8 degrees Celsius is added to the packed cells. After mixing well by vigorous shaking the solution was kept at $2-4^{0} \mathrm{C}$ for half an hour. It was centrifuged then at $3000 \mathrm{rpm}$ for 5 minutes prior to use.

\section{Determination of the hemoglobin concentration}

This was done by the Cynomethemoglobin method (CMG method). For this $20 \mu$ of blood was added to $5 \mathrm{ml}$. of Drabkin's solution and mixed well. After keeping at room temperature for five minutes the absorbance of the solution was determined in a spectrophotometer $530 \mathrm{~nm}$, and the haemoglobin content was determined by calibrating it against the standard curve of hemoglobin.

\section{Determination of the G6PD activity}

In a test tube marked $(\mathrm{T})$ the reagents are added in following sequence

\begin{tabular}{|l|l|}
\hline Addition Sequence & Test \\
\hline Working reagent & $1000 \mu \mathrm{l}$. \\
\hline Hemolysate & $25 \mu \mathrm{l}$. \\
\hline
\end{tabular}

After mixing well and after an initial delay of 180 seconds, the absorbance of the test is measured at a wavelength of $340 \mathrm{~nm}$. This measurement is continued at an interval of one minute for next three minutes and the mean absorbance change per minute $(\Delta \mathrm{A} / \mathrm{min})$ is calculated.

Calculations

G6PD activity in $\mathrm{U} / \mathrm{g} \mathrm{Hb}=\Delta \mathrm{A} / \mathrm{Min} \mathrm{X}$

$6.22 \times \mathrm{Hb}(\mathrm{g} / \mathrm{dl})$. 
$=\Delta \mathrm{A} / \mathrm{Min} \mathrm{X}$

Where; $100=$ Factor to convert to $100 \mathrm{ml}$.

$224=$ Total assay volume to sample volume,

$6.22=$ Millimolar absorptivity of the NADPH at $340 \mathrm{~nm}$,

$\mathrm{Hb}(\mathrm{g} / \mathrm{dl})=$ Hemoglobin concentration.

Normal reference range : G6PD activity (at $30^{\circ} \mathrm{C}$ ) in $\mathrm{U} / \mathrm{g} \mathrm{Hb}=4.6-13.5 \mathrm{U} / \mathrm{g} \mathrm{Hb}$.

\section{Statistical analysis}

The deficient numbers of G6PD deficiency were segregated for both case and non case population. Odds ratio and chi square values were calculated and the lower and upper limit of the Odds ratio (OR) was found at $95 \%$ confidence interval. Significance of the lower and upper range of OR was found out at $95 \%$ confidence interval.

\section{Results}

Among the 100 cases, 12 persons were found to have a G6PD activity below the normal reference range (Table-1). Among the 60 non case people this deficiency was found in 2 persons. So, in the present study the G6PD deficiency among the Rajbanshis is found to be 12 percent, and about 3.33 percent in the non case population. Chi square $\left(\chi^{2}\right)$ and Odds ratio (OR) was found to be 2.05 and 3.95 respectively. The lower and upper confidence limit for the population Odds ratio were $3.95^{1-1.96 / \sqrt{2} .05}=3.58$ and $3.95^{1+1.96 / \sqrt{ } .05}=25.93$ respectively. We concluded with $95 \%$ confidence that the population OR was somewhere between 3.58 and 25.93. Since the interval did not include 1, we concluded that in the Rajbangshi population (cases) G6PD deficiency is more likely to be present than in the non Rajbangshi (noncase) group.

The overall distribution of the G6PD activity in both Cases and Controls are shown in the figure 1 and table 1 respectively.

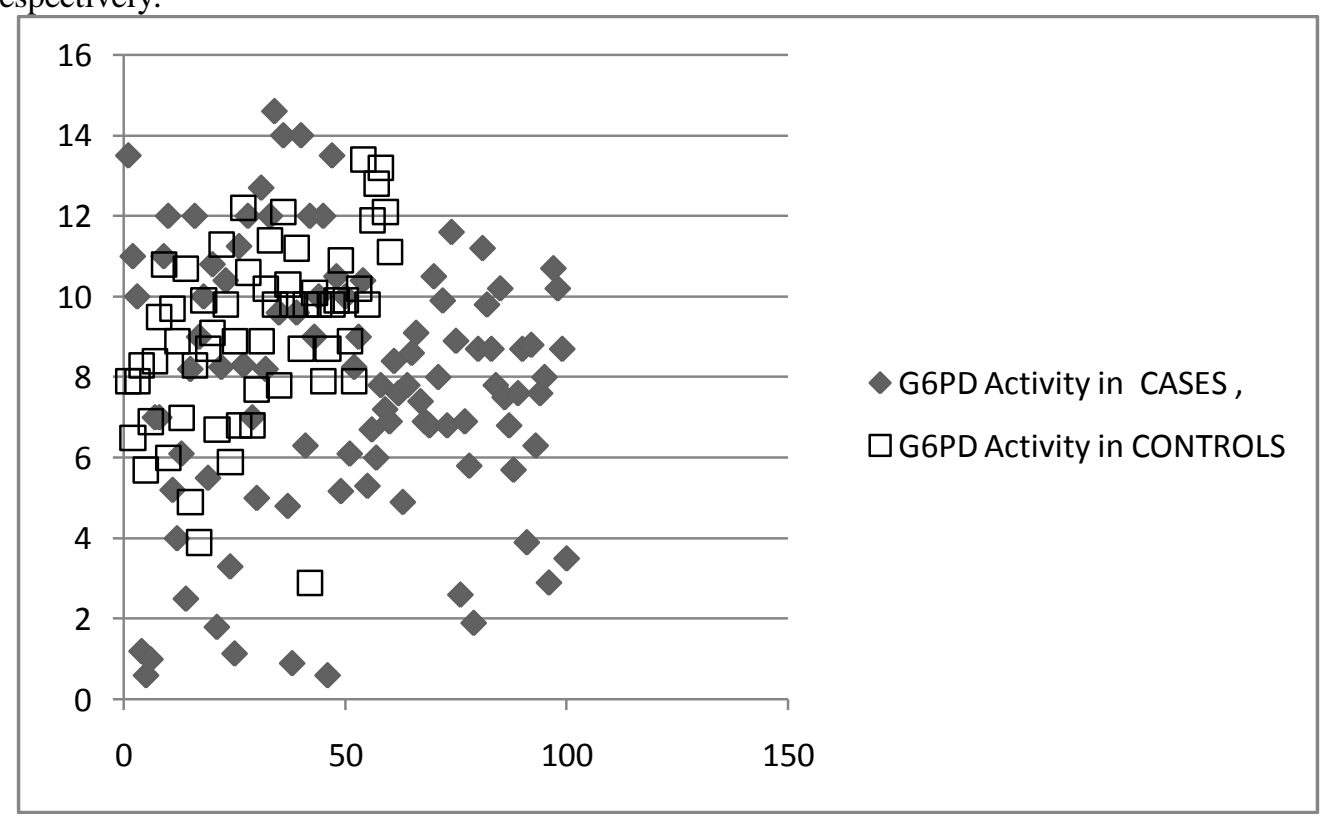

Figure 1

Distribution of G6PD activity in cases $(n=100)$ and control $(n=60)$ groups

Table 1

The distribution of the G6PD activity in the Cases and Controls (Normal reference range of G6PD activity in $\mathrm{U} / \mathrm{g} \mathrm{Hb}=4.6-13.5 \mathrm{U} / \mathrm{g}$ hemoglobin).

\begin{tabular}{lll}
\hline & G6PD inadequate & G6PD adequate \\
\hline Cases & 12 & 88 \\
\hline Non cases & 2 & 58 \\
\hline
\end{tabular}

Chi square $\left(\chi^{2}\right)=2.05, \mathrm{OR}=3.95$ 
The lower and upper confidence limit for the population Odds ratio are $3.95^{1-1.96 / \sqrt{ } 2.05}=3.58$ and $3.95^{1+1.96 / \sqrt{ } 2.05}=$ 25.93 respectively. We conclude with $95 \%$ confidence that the population OR is somewhere between 3.58 and 25.93.

\section{Discussion}

More than 200 million people all over the world suffer from G6PD deficiency ${ }^{13}$ and this deficiency is found to be distributed in a heterogeneous manner among different population groups of the world. In India also the G6PD deficiency is found to be distributed in a heterogeneous pattern as already discussed above. In the present study the G6PD deficiency in the Rajbangshis of Sushrutanagar area of the Darjeeling district of West Bengal is found to be about 15 percent which is definitely higher than the overall rate of 2-5 percent of G6PD deficiency in the general population of India ${ }^{9}$. Although this study comprised of about one hundred cases selected randomly from about 15000 populations of Rajbangshis of the Sushrutanagar area, yet the high percentage of G6PD deficiency in the studied cases indicates an overall high rate of G6PD deficient people among the Rajbangshi population of Sushrutanagar. Simultaneously, the distribution rate is found to be only 3 percent in the non Rajbangshi population of the same area. The genetic heterogeneity which is found in some enzymopathies may be one of the important causes for this noted heterogeneous distribution of the G6PD deficiency among the individuals, and indeed over 400 variants of G6PD have been described already ${ }^{13}$. A strong evidence of significant difference between frequency of G6PD deficiency in Tribal and non-tribal group of newborns with more frequency of G6PD deficiency in tribal newborns with neonatal hyperbilirubinemia. Prevalence ratios among Non-tribal and Tribal neonates were $12.00 \%$ and $23.07 \%$ respectively. This difference is statistically significant $(\chi 2=2.31 ; \mathrm{df}=1 \mathrm{p}<0.05)^{14}$.

Other reports of G6PD deficiency are shown variability in different ethnic populations like Parsee ${ }^{16}$, Brahmin $^{17}$, Jat ${ }^{18}$ and Vataliya Prajapati ${ }^{19}$ etc. The frequency is higher among the tribals than the caste populations ${ }^{20}$. According to Bhasin and Walter ${ }^{21}$, the frequency of G6PD among Indian Population as a whole ranges from complete absence to $27 \%$. It is higher among scheduled tribes as compared to other ethnic groups. G6PD deficient allele frequency is comparatively higher in North and West Indian Zones, whereas in South India it is uniformly low except in Andhra Pradesh and Tamil Nadu. Prevalence of G6PD deficiency is generally 0-10\%, although some community may have higher prevalence: $27.5 \%$ for the Angami Nagas, a tribal group in Northern India ${ }^{22}$

Abnormalities in primary DNA or protein sequence have been established in a number of the G6PD variants and in almost all cases the alteration there is one or more base substitutions, leading to an amino acid replacement and not a deletion in the protein ${ }^{13}$. Evidence in the abnormality in structure is seen in the differences in electrophoresis mobility, enzyme kinetics, pH optimum, and heat stability; and these differences result in great variation of clinical severity, ranging from nonspherocytic hemolytic anemia without demonstrable oxidant stress (particularly shortly after birth), through hemolytic anemia only when stimulated by marked to mild oxidant stress, to no clinically detectable abnormality ${ }^{23}$. The normal G6PD is designated as type B, but about $20 \%$ of individuals of African descent have a G6PD, designated as type A+ that differs by a single amino acid and is electrophoretically distinguishable but functionally normal. Among the clinically significant G6PD variants, the most common, the A-type, is due to two base substitutions and is encountered primarily in individuals with ancestral origins in Central Africa ${ }^{24}$. This variety of the G6PD enzyme has abnormal kinetic property and is found in about 11 percent of African descended males in the United States. A second variety of G6PD is encountered in the peoples of the Mediterranean circumlittoral, particularly the Sardinians and Sephardic Jews. This variant is more severe than the A-variety and may result in non spherocytic hemolytic anemia ${ }^{24}$. A third relatively common and slightly less severe variant occurs in southern Chinese population. Till now no such genetic data is available for the population of the Rajbangshis of the Sushrutanagar and so, a detailed study is required in this area to properly characterize the G6PD variety of this region where the G6PD deficiency has been found to be relatively higher than the general population of India.

\section{References}

[1]. Vasudevan, D.M. and Srikumari, S. (1998), Text Book of Biochemistry for Medical Students, 2nd edn. Jaypee Brothers Medical Publishers Ltd., New Delhi, p 59.

[2]. Ghai, O.P. (2001), Essentials of Paediatrics, $5^{\text {th }}$ edn. Mehta Publishers, New Delhi, p 102-103.

[3]. Vasudevan, D.M. and Srikumari, S. (1998), Text Book of Biochemistry for Medical Students, $2^{\text {nd }}$ edn. Jaypee Brothers Medical Publishers Ltd. New Delhi, p103-104.

[4]. Wendell, Ross. and H, Franklin Bunn. (2001), Harrison's Principle of Internal Medicine, vol 1,15 ${ }^{\text {th }}$ edn. (International edition). MCgraw Hills, Singapore, p 685.

[5]. Vasudevan, D.M.and Srikumari, S. (1998), Text Book of Biochemistry for Medical Students, $2^{\text {nd }}$ Edition. Jaypee Brothers Medical Publishers Ltd. New Delhi, p 305.

[6]. Cai, W., Filosa, S., Martini, G. (1994), DNA haplotypes in the G6PD Gene Cluster studied in the Chinese Li Population and their relationship to G6PD. HumHered. 44 (5), 279-86. 
[7]. Iwak, K., Hiron , A., Matsuoka, H., Kawamoto, F., Herie, T Link., Tantular, I S., Dachlan, I P., Notopuro, H., Hidayah, N I ., Salim, A M., Fujii, H., Miwa, S., Ishii, A. (2001), Distribution of Glucose 6 Phosphate Dehydrogenase Mutations in South East Asia. HumGenet. 108(6), 445-9.

[8]. Robert, K Murray. (2000), Harper's Biochemistry, $25^{\text {th }}$ edn. Appleton \& Lange, Stanford, Connecticut, p 767.

[9]. Talwar, G.P., Srivastava, L M., Moudgil, U D. (1989), Text Book of Biochemistry and Human Biology, $2^{\text {nd }}$ edn. Elements of Human Genetics, Chapter-53,Section -VII, Page-636.

[10]. Saha, N., Tay, J S. (1990), Genetic studies among the Nagas and Hmars of Eastern India. Am J Phys Antropol. 82(1), 101-12.

[11]. Chatterjee, M.N. and Shinde, Rana. (1997), $2^{\text {nd }}$ edition, Test Book of Medical Biochemistry, Jaypee Brothers Medical Publishers Ltd. New Delhi, page: 401

[12]. Kachmar, J. F. and Moss, D. W. (1976), Enzymes in fundamentals of Clinical Chemistry. N.W.Teitz, Saunders, Philadelphia, p 666670.

[13]. Gross, R T., Hurwitz, R E., Marks, P A. (1978), Red cell Glucose 6 Phosphate Dehydrogenase Deficiency. J.Clin. Invest. $37,176$.

[14]. Manik Mondal, Asok Kumar Datta, Syamali Mandal, Pradeep Kumar Das. Study of Glucose 6 phosphate dehydrogenase deficiency in neonatal jaundice. IOSR Journal of Pharmacy and Biological Sciences. Volume 1, Issue 5 (July-August 2012), PP 30-36.

[15]. Baxi, V. Balakrishnan, J. V. Undevia, and L. D. Sanghvi, "Glucose-6-phosphate dehydrogenase deficiency in the Parsee community, Bombay.," Indian journal of medical sciences, vol. 17, pp. 493-500, 1963.

[16]. A. Santhi and M. P. Sachdeva, "Glucose-6-phosphate dehydrogenase deficiency among the jats and brahmins of sampla (Haryana)," The Anthropologist, vol. 6, no. 4, pp. 291-292, 2004.

[17]. K. N. Saraswathy and S. Aggarwal, "Study of glucose-6- phosphate dehydrogenase deficiency and sickle cell anemia among the Tamil Brahmins of Delhi," The Anthropologist, vol. 7, no. 1, pp. 45-47, 2005.

[18]. A. Santhi and M. P. Sachdeva, "Glucose-6-phosphate dehydrogenase deficiency among the jats and brahmins of sampla (Haryana)," The Anthropologist, vol. 6, no. 4, pp. 291-292, 2004.

[19]. S. C. Gupte, A. N. Shaw, and K. C. Shah, "Hematological findings and severity of G6PD deficiency in Vataliya Prajapati subjects," Journal of Association of Physicians of India, vol. 53, pp. 1027-1030, 2005.

[20]. V. Tripathy and B. Reddy, "Present status of understanding on the G6PD deficiency and natural selection," Journal of Postgraduate Medicine, vol. 53, no. 3, pp. 193-202, 2007.

[21]. M. K. Bhasin and H. Walter, Genetic of Caste and Tribes of India, Kamla-Raj Enterprises, Delhi, India, 2001.

[22]. P. K. Seth and S. Seth, "Biogenetical studies of Nagas: glucose-6-phosphate dehydrogenase deficiency in Angami Nagas.," Human Biology, vol. 43, no. 4, pp. 557-561, 1971.

[23]. Wendell, Ross., H, Franklin Bunn. (1998), Harrison's Principle of Internal Medicine, vol 1, 14 ${ }^{\text {th }}$ edn. (International edition). MCgraw Hills, Singapore, p 663.

[24]. Wendell, Ross., H, Franklin Bunn. (1998), Harrison's Principle of Internal Medicine, vol 1, $14^{\text {th }}$ edn. (International edition). MCgraw Hills, Singapore, p 663-64. 